\title{
A social work study on the effect of emotional intelligence training on communication skills
}

\author{
Sahar Mirghobad Khodarahmi ${ }^{a^{*}}$, Amir Hesam Khjeh ${ }^{b}$, Mehdi Poorkord $^{c}$ and Maliheh Yaghoubzadeh $^{d}$
}

${ }^{a}$ M.A. in counseling, Counseling Department, University of Islamic Azad University Khomeinishahr Branch, Daneshjou Blvd, Esfahan, Iran

${ }^{b}$ M.A. in family counseling, Counseling Department, Esfahan University Branch, Esfahan, Iran

${ }^{c}$ M.A. in Psychology, Department of Psychology, University of Mohaghegh Ardabili, Ardabil, Iran

${ }^{d}$ M.S. in General Psychology, Islamic Azad University Branch of Khorasgan, Esfahan, Iran

\section{H R O N I C L E}

\section{Article history:}

Received May 2, 2013

Received in revised format

25 June 2013

Accepted 7 July 2013

Available online

July 82013

Keywords:

Emotional intelligence

Communication skills

Counseling

\section{Introduction}

Having a good communication skill is one of the critical success factors to succeed in today's social life. When a person does not have such communication skills, he/she may lose his/her confidence and over the long term may suffer from depression (Salovey et al., 2002; Hargie, 2010). Therefore, it is important to find possible remedies to help young people improve their communication skills. Fernandez-Berrocal et al. (2006) examined the relationship between emotional, anxiety and depression among a group of people and reported that emotional abilities were an essential part of psychological adjustment. Ciarrochi et al. (2001) investigated whether emotional intelligence (EI) can be reliably and validly measured in adolescents or not. They asked 131 studends to completer a

*Corresponding author. Tel: +989373157212

E-mail address: mirghobadmelika@yahoo.com (S. Mirghobad Khodarahmi)

(C) 2013 Growing Science Ltd. All rights reserved. doi: $10.5267 /$ j.ms 1.2013 .07 .006 
self-report measure of emotional intelligence (SEI) developed by Schutte et al. (1998) and other questionnaires.

They were then induced into either a positive, negative, or neutral mood and requested to complete a task that assessed mood management attitude. They found that EI was reliably measured in adolescents, was higher for females than males, and was positively related to skill for identifying emotional expressions, amount of social support, extent of satisfaction with social support, and mood management behaviour. These relationships were hold even after controlling for two constructs that potentially overlap with EI, namely self-esteem and trait anxiety. Therefore, the study offered some evidence that the SEI was a distinctive and useful measure.

Emotional intelligence is one of the most commonly skills used for improving social and communication skills ( Matthews et al. 2004; Salovey \& Mayer, 1989). Segrin (1992) stated that the nature of social skill deficits is highly associated with depression. Rogers et al. (2006) suggested that improving social skills could reduce people's stress. Lopes et al. (2003) investigated links between emotional intelligence, measured as a set of abilities, and personality traits, as well as the contribution of both to the perceived quality of one's interpersonal relationships. Lopes et al. (2004), in another study, performed two studies and reported positive relationships between the ability to manage emotions and the quality of social interactions, supporting the predictive and incremental validity of an ability measure of emotional intelligence.

Jarvis et al. (2005) suggested improving social skills to get rid of alcohol and drug dependence. Trinidad and Johnson (2002) investigated the association between emotional intelligence and early adolescent tobacco and alcohol use. Schutte et al. (2001) examined the relationship between emotional intelligence and interpersonal relations in seven cases. In Studies 1 and 2, the volunteers with higher scores for emotional intelligence had higher scores for empathic perspective taking and self-monitoring in social situations. In Study 3, the participants with higher scores for emotional intelligence hold higher scores for social skills. In Study 4, the participants with higher scores for emotional intelligence represented more cooperative responses toward partners. In Study 5, the participants with higher scores for emotional intelligence maintained higher scores for close and affectionate relationships. In Study 6, the participants' scores for marital satisfaction were relatively higher when they ranked their marital partners higher for emotional intelligence. In Study 7, the

participants predicted greater satisfaction in relationships with partners described as having emotional intelligence.

In this paper, we present an empirical investigation to study the effect of emotional intelligence on communication skills. The organization of this paper first presents details of the survey in section 2 , the results of our investigation are given in section 3 and concluding remarks are given in the last to summarize the contribution of the paper.

\section{The proposed study}

This paper presents an empirical study to measure the effect of training emotional intelligence on communication skills among 32 teenagers who visited counseling center in city of Esfahan, Iran during the year of 2011. The people were divided into two groups of control and witness and using a questionnaire consists of 34 questions we measure the effect of training emotional intelligence on improving communication skills. The questionnaire consists of five groups of questions including the skills of listening, understanding of a message, emotion regulation, Insight into the communication processes and decisive related communication. Table 1 demonstrates the summary of basic statistics between two groups before and after performing test. 
Table 1

The summary of basic statistics before and after accomplishment of the test

\begin{tabular}{lccccc}
\hline & & \multicolumn{2}{c}{ Pre-test } & \multicolumn{2}{c}{ Post test } \\
\cline { 2 - 6 } & & Mean & $\begin{array}{c}\text { Standard } \\
\text { deviation }\end{array}$ & Mean & $\begin{array}{c}\text { Standard } \\
\text { deviation }\end{array}$ \\
\hline \multirow{2}{*}{ Communication skills } & Experiment & 90.75 & 11.79 & 111.19 & 6.34 \\
\hline \multirow{2}{*}{ Emotion regulation } & Control & 98.31 & 11.59 & 99.11 & 11.96 \\
\hline \multirow{2}{*}{ Understanding of a message } & Experiment & 13.87 & 4.66 & 20.31 & 0.94 \\
\hline \multirow{2}{*}{ Listening } & Control & 13.68 & 5.27 & 14.81 & 4.87 \\
\hline Insight into the communication processes & Experiment & 25.26 & 3.28 & 28.86 & 3.85 \\
& Control & 24.26 & 3.73 & 25.33 & 4.33 \\
\hline \multirow{2}{*}{ Decisive related communication } & Experiment & 18.13 & 2.79 & 21.13 & 1.84 \\
\hline & Control & 17.2 & 2.75 & 18.86 & 1.80 \\
\hline
\end{tabular}

As we can observe from the results of Table 1, there is an increase on mean of the first five components of the Table 1 after the test has been completed.

\section{The results}

In this section, we present the results of ANOVA test between emotional intelligence and different components of the communication skills.

Table 2

The results of ANOVA test

\begin{tabular}{lcccccccc}
\hline Source of changes & $\begin{array}{c}\text { Sum of } \\
\text { Squares }\end{array}$ & df & $\begin{array}{c}\text { Mean of } \\
\text { squares }\end{array}$ & F & P-value & $\begin{array}{c}\text { Effect } \\
\text { Statistics } \\
\text { power }\end{array}$ \\
\hline Communication skills & 2029.3 & 1 & 2029.3 & 107.31 & 0 & 0.79 & 1 \\
Emotion regulation & 108.94 & 1 & 108.94 & 16.21 & 0.001 & 0.42 & 0.97 \\
Understanding of a message & 196.54 & 1 & 196.54 & 7.16 & 0.01 & 0.2 & 0.73 \\
Listening & 26.67 & 1 & 26.67 & 4.73 & 0.03 & 0.14 & 0.55 \\
Insight into the communication processes & 91.7 & 1 & 91.7 & 52.62 & 0 & 0.7 & 1 \\
Decisive related communication & 0.359 & 1 & 0.359 & 0.352 & 0.55 & 0.01 & 0.08 \\
\hline
\end{tabular}

Based on the results of Table 2, there is a meaningful relationship between emotional intelligence and various skills including emotion regulation, understanding of a message, listening and insight into the communication processes when the level of significance is five percent. However, decisive related communication skills had no meaningful impact.

\section{Conclusion}

In this paper, we have presented an empirical investigation to find out whether an improvement on emotional intelligence could contribute to people's social skills such as communication skills. The proposed study has adopted a questionnaire and distributed among some young students who were visiting counseling center in city of Esfahan, Iran. The results of our investigation have confirmed that an increase in emotional skills could contribute people's social skills.

\section{Acknowledgment}

The authors would like to thank anonymous referees for constructive comments on earlier version of this work. 


\section{References}

Ciarrochi, J., Chan, A. Y., \& Bajgar, J. (2001). Measuring emotional intelligence in adolescents. Personality and individual differences, 31(7), 1105-1119.

Fernandez-Berrocal, P., Alcaide, R., Extremera, N., \& Pizarro, D. (2006). The role of emotional intelligence in anxiety and depression among adolescents.Individual Differences Research, 4(1), 16-27.

Hargie, O. (2010). Skilled interpersonal communication: Research, theory and practice. Routledge.

Jarvis, T. J., Tebbutt, J., Mattick, R. P., \& SHAND, M. A. (2005). Treatment approaches for alcohol $\&$ drug dependence. Adolescence, 254, 265.

Lopes, P. N., Salovey, P., \& Straus, R. (2003). Emotional intelligence, personality, and the perceived quality of social relationships. Personality and individual Differences, 35(3), 641-658.

Lopes, P. N., Brackett, M. A., Nezlek, J. B., Schütz, A., Sellin, I., \& Salovey, P. (2004). Emotional intelligence and social interaction. Personality and Social Psychology Bulletin, 30(8), 1018-1034.

Matthews, G., Roberts, R. D., \& Zeidner, M. (2004). Seven myths about emotional intelligence. Psychological Inquiry, 15(3), 179-196.

Rogers, P., Qualter, P., Phelps, G., \& Gardner, K. (2006). Belief in the paranormal, coping and emotional intelligence. Personality and individual differences, 41(6), 1089-1105.

Salovey, P., \& Mayer, J. D. (1989). Emotional intelligence. Imagination, cognition and personality, 9(3), 185-211.

Salovey, P., Mayer, J. D., \& Caruso, D. (2002). The positive psychology of emotional intelligence. Handbook of positive psychology, 159, 171.

Schutte, N., Malouff, J., Hall, L., Haggerty, D., Cooper, J., Golden, C., \& Dornheim, L. (1998). Development and validation of a measure of emotional intelligence. Personality and Individual Differences, 25, 167-177.

Schutte, N. S., Malouff, J. M., Bobik, C., Coston, T. D., Greeson, C., Jedlicka, C., ... \& Wendorf, G. (2001). Emotional intelligence and interpersonal relations.The Journal of Social Psychology, 141(4), 523-536.

Segrin, C. (1992). Specifying the nature of social skill deficits associated with depression. Human Communication Research, 19(1), 89-123.

Trinidad, D. R., \& Johnson, C. A. (2002). The association between emotional intelligence and early adolescent tobacco and alcohol use. Personality and Individual Differences, 32(1), 95-105. 